\title{
INFLUÊNCIA DO SUBSTRATO, TAMANHO DE SEMENTES E MATURAÇÃO DE FRUTOS NA FORMAÇÃO DE MUDAS DE PITANGUEIRA ${ }^{1}$
}

\author{
LUIS EDUARDO CORREAA ANTUNES ${ }^{2}$, LUCIANO PICOLOTTO ${ }^{3}$, \\ GERSON KLEINICK VIGNOLO ${ }^{4}$, MICHEL ADRIGHI GONCALVES ${ }^{4}$
}

RESUMO- Os experimentos foram realizados na Embrapa Clima Temperado, e as muda , conduzidas em bandejas de poliestireno expandido, de 72 células, colocadas em casa de vegetação com irrigação manual. O delineamento experimental adotado nos experimentos foi o inteiramente casualizado, em esquema fatorial, utilizando-se de quatro repetições com 12 sementes cada (Experimento 1) e três repetições com 18 sementes cada (Experimento 2). Os tratamentos do Experimento 1 foram o tamanho de semente (média e pequena) e o substrato (Plantimax ${ }^{\circledR}$, vermiculita e fibra de coco). Já no Experimento 2, os tratamentos utilizados foram as seleções de pitangueira (67 e172) e a maturação do fruto (parcial e totalmente maduro). Os parâmetros avaliados foram: porcentagem de emergência, comprimento da parte aérea e da maior raiz $(\mathrm{cm})$, número de folhas por planta, massa da matéria seca da raiz e da parte aérea (g), sementes brocadas, dormentes e não emergidas. As sementes de tamanho médio foram superiores às pequenas em todas as variáveis avaliadas. O substrato Plantimax ${ }^{\circledR}$ proporcionou maior massa da matéria seca total do que a fibra de coco, porém não diferindo da vermiculita. A seleção 172 apresentou maior porcentagem de emergência e menor dormência do que a 67. As sementes oriundas dos frutos totalmente maduros apresentaram maior dormência e menor número de folhas do que as sementes de frutos parcialmente maduros. Conclui-se que a utilização de sementes de tamanho médio e do substrato Plantimax ${ }^{\circledR}$ proporciona melhor desenvolvimento inicial de mudas de pitangueira. O grau de maturação dos frutos afeta o processo de dormência das sementes e o desenvolvimento inicial das mudas de pitangueira.

Termos para indexação: Eugenia uniflora, pitanga e propagação.

\section{INFLUENCE OF THE SUBSTRATE, SEED SIZE AND FRUIT MATURATION IN THE FORMATION OF CHERRY TREE SEEDLINGS}

\begin{abstract}
The experiments were carried out at Embrapa Temperate Climate and the seedlings conducted in polystyrene trays with 72 cells, placed in a greenhouse with manual irrigation. The experimental design used in the experiments was completely randomized in a factorial design, using four replicates with 12 seeds each (Experiment 1) and three replicates of 18 seeds each (Experiment 2). The treatments of experiment 1 were the seed size (medium and small) and substrate (Plantimax ${ }^{\circledR}$, vermiculite, coconut fiber). In the second experiment the treatments were the selections of Surinam cherry (67 and 172) and fruit ripening (partially and fully mature). The parameters were evaluated: emergency percentage, shoot length and the longest root $(\mathrm{cm})$, number of leaves per plant, dry mass of root and shoot $(\mathrm{g})$, brocade seeds, dormant and not emerged. The seeds of medium size were higher than little seeds in all variables. The substrate Plantimax ${ }^{\circledR}$ provided greater total dry matter than the coconut fiber, but no difference from the vermiculite. The selection 172 had a higher percentage of emergency and lower dormancy than 67 . Seeds from fully ripe fruits showed higher dormancy and fewer leaves than partially ripe fruit seeds. It is concluded that the use of medium size seed and the substrate Plantimax ${ }^{\circledR}$ improve seedling development of Surinam cherry. The degree of ripeness of the fruit affects the process of seeds dormancy and initial seedling of Surinam cherry.
\end{abstract}

Index terms: Eugenia uniflora, cherry and propagation.

\footnotetext{
1(Trabalho 131-12). Recebido em: 10-04-2012. Aceito para publicação em: 10-08-2012.

${ }^{2}$ Eng. Agrôn., Dr., Pesquisador da Embrapa Clima Temperado, Pelotas-RS. E-mail: luis.antunes@embrapa.br

${ }^{3}$ Eng. Agrôn., Dr., Bolsista PNPD/Capes da Embrapa Clima Temperado Pelotas-RS. E-mail: picolotto@gmail.com

${ }^{4}$ Eng. Agrôn., Doutorando Universidade Federal de Pelotas, Pelotas-RS. E-mails: gerson_vignolo@yahoo.com.br, aldrighimichel@ gmail.com
} 


\section{INTRODUÇ̃̃O}

No Sul do Brasil, existe grande diversidade de frutíferas nativas, dentre as quais se destaca a pitangueira, que é pertencente à família Myrtaceae (RASEIRA et al., 2004), gênero Eugenia e espécie Eugenia uniflora L. (LIRA JÚNIOR et al., 2007). O fruto é do tipo baga, globoso, deprimido nos polos, com sete a 10 sulcos, no sentido longitudinal, medindo $1,75 \mathrm{~cm}$ de diâmetro, $1,40 \mathrm{~cm}$ de altura, peso entre 3,0 e 4,8 g (DONADIO, 2007), apresentando geralmente uma a duas sementes, esporadicamente três (LIRA JÚNIOR et al., 2007).

A maioria dos pomares de pitangueira são formados a partir de mudas resultantes da propagação por sementes. Também se recomenda o uso da propagação vegetativa por enxertia de garfagem no topo (em fenda cheia e a inglesa simples) que são as mais eficientes, por enxertia do tipo borbulha de placa em janela aberta e estaquia, esta última não é usual e exige cuidados especiais de manejo das estacas. Para a propagação por sementes, deve-se colher frutos maduros, despolpar as sementes, lavá-las em água corrente, colocá-las para secar à sombra e semeá-las o mais rápido possível, visando a garantir seu potencial germinativo (LIRA JÚNIOR et al., 2007). A qualidade máxima da semente é associada ao acúmulo de peso máximo, também chamado como maturidade fisiológica (CASTRO et al., 2004). O acompanhamento do desenvolvimento das sementes é feito com base em modificações como tamanho, teor de água, conteúdo de matéria seca, germinação e vigor (DIAS, 2001). Oliveira et al. (2005) afirmaram que, dentro de um mesmo lote de sementes, aquelas consideradas pequenas podem apresentar menor emergência de plântulas e vigor do que as sementes consideradas médias e grandes. Carvalho e Nakagawa (2000) mencionam que, de modo geral, as sementes de maior tamanho armazenam maior quantidade de substâncias de reserva durante a fase de desenvolvimento, o que proporciona embriões mais desenvolvidos, sendo consideradas sementes de maior vigor. A maior quantidade de reserva aumenta a probabilidade de sucesso no estabelecimento da plântula (LORENZI, 2008), pois permite a sobrevivência por maior tempo em condições ambientais desfavoráveis.

De acordo Avila et al. (2009), o processo de maturação é caracterizado por uma série de mudanças morfológicas, fisiológicas e funcionais. Essas mudanças podem influenciar a qualidade das sementes e podem ter relação, segundo Sartor et al. (2010) com o momento de sua coleta. Na pitangueira, a coloração dos frutos mostrou-se um parâmetro prático e eficaz para a identificação do ponto de maturidade fisiológica, observado pela coloração vermelha, aos 56 dias após a antese (AVILA et al., 2009). Segundo Dias (2001), muitos estudos feitos com maturação de sementes de diversas espécies apontam o ponto de máximo conteúdo de massa seca como o melhor e mais seguro indicativo de que as sementes atingiram a maturidade fisiológica. Comprovou-se, por Santos et al. (2002), em pitangas, que a massa seca do fruto aumentou até um determinado estágio, estabilizando-se posteriormente. Acredita-se que isto ocorra também com as sementes, no entanto poucas informações estão disponíveis até o momento.

A qualidade das mudas também pode estar relacionada com o tipo de substrato utilizado durante o período de desenvolvimento das mudas. Fatores como aeração, estrutura e capacidade de retenção de umidade, entre outros, podem variar entre os diferentes substratos, favorecendo ou prejudicando a germinação das sementes (POPINIGIS, 1985). Para Kampf (2000), o substrato deve ser suficientemente poroso, a fim de permitir trocas gasosas eficientes, favorecendo a respiração das raízes e a atividade dos microrganismos do meio. Outra característica importante dos substratos é sua capacidade de retenção de água. Em substratos com partículas muito pequenas, como a matéria orgânica bem humificada, a dificuldade de drenagem é considerável.

Sendo assim, objetivou-se avaliar o efeito de diferentes substratos, tamanho de sementes e maturação de frutos na formação de mudas de seleções de pitangueira.

\section{MATERIAL E MÉTODOS}

Os frutos de pitangueira utilizados nos experimentos foram obtidos de plantas das seleções 67 e 172 conduzidas em pomar da Embrapa Clima Temperado, Pelotas-RS, localizada na latitude $31,5^{\circ}$ e longitude $52,21^{\circ}$, a $70 \mathrm{~m}$ de altitude.

Experimento 1: O delineamento experimental adotado foi em bloco inteiramente casualizado,em esquema fatorial $2 \times 3$ (tamanho da semente $\mathrm{x}$ substratos), utilizando-se de quatro repetições com 12 sementes cada. Os tratamentos foram dois tamanhos de sementes (média e pequena) e três substratos (Plantimax $^{\circledR}$, vermiculita e fibra de coco).

Foram coletados frutos da seleção 67 e encaminhados ao laboratório para a extração manual das sementes e posterior lavagem em água corrente. Após a lavagem, as sementes foram colocadas em papel toalha para secar a sombra durante 48 horas. Realizada a secagem, procedeu-se a separação das sementes em duas classes de tamanho, tomando-se 
como base o diâmetro das sementes, onde as de tamanho pequeno e médio tinham $6,0 \mathrm{~mm}$ e $10,0 \mathrm{~mm}$, respectivamente.

A semeadura foi realizada em novembro de 2009 , sete dias após a extração das sementes, as quais foram colocadas para germinar em bandejas de poliestireno expandido de 72 células sobre bancadas de ferro, com $1 \mathrm{~m}$ de altura e mantidas em estufa agrícola com teto plástico, laterais com tela antiafídeo e sombrite clarite.

Os substratos foram umedecidos manualmente de acordo com a demanda hídrica. Aos 90 dias após a semeadura, foram avaliados: a porcentagem de emergência, o comprimento da parte aérea e da maior raiz $(\mathrm{cm})$, massa da matéria seca da raiz, da parte aérea e total e o número de folhas por planta. Posteriormente, a parte aérea e as raízes foram acon $\neg$ dicionadas em sacos de papel e colocadas no interior de uma estufa com circulação forçada, à temperatura de $65^{\circ} \mathrm{C}$, até atingir peso constante, para a determi $\neg$ nação da massa da matéria seca da parte aérea e das raízes das mudas.

Experimento 2: O delineamento experimental foi em bloco inteiramente casualizado, em esquema fatorial $2 \times 2$ (seleções e estágios de maturação), com três repetições de 18 plantas. Utilizaram-se frutos de pitangueira das seleções 67 e 172, selecionados em duas classes: transição da cor verde para início da pigmentação e totalmente vermelha. Os frutos foram preparados no laboratório, conforme descrito no Experimento 1. A semeadura foi realizada na primeira quinzena do mês de maio de 2010. Utilizaram-se bandejas de poliestireno expandido de 72 células e como substrato a vermiculita de granulometria média. O material experimental foi mantido em casa de vegetação, em temperatura ambiente, e com irrigação realizada manualmente, conforme a necessidade.

As avaliações foram: porcentagem de emergência, sementes brocadas, germinadas não emergidas e dormentes (não germinadas), comprimento da parte aérea $(\mathrm{cm})$ e do número de folhas, ambas realizadas em 13-10-10, exceto emergência (\%) (realizada semanalmente a partir de 16-07-10).

Os dados de ambos os experimentos foram submetidos à análise de variância, e as médias, comparadas pelo teste de Tukey, a 5\% de probabilidade, através do programa estatístico Winstat (MACHADO; CONCEIÇÃO, 2003).

\section{RESULTADOS E DISCUSSÃO}

Experimento 1: Aos 90 dias após a semeadura, as sementes de tamanho médio apresentaram maior porcentagem de emergência $(80,55 \%)$ (Tabela 1). Já Klein et al. (2007a) observaram que sementes grandes de pitangueira apresentaram emergência de $92 \%$. Geralmente, sementes maiores são bem nutridas em seu desenvolvimento, tendo embriões bem formados e com mais substâncias de reserva (CARVALHO; NAKAGAWA, 2000).

Para a variável número de folhas por planta, as sementes de tamanho médio destacaram-se $(8,96)$ quando comparadas à quantidade de folhas geradas pelas plantas oriundas de sementes pequenas $(7,16)$. Com relação ao comprimento da maior raiz, as sementes de tamanho médio apresentaram 15,65 $\mathrm{cm}$, valor este superior ao encontrado nas sementes pequenas. O substrato Plantimax ${ }^{\circledR}$ proporcionou maior número de folhas $(9,44)$ do que os substratos vermiculita $(7,98)$ e fibra de coco $(6,76)$. Porém, o uso de diferentes substratos não causou diferença na porcentagem de emergência e no comprimento da maior raiz (Tabela 1).

Houve interação significativa entre o fator tamanho de semente e o substrato para a variável comprimento da parte aérea (Tabela 1). Independentemente do substrato utilizado, as sementes médias apresentaram comprimento da parte aérea superior, sendo de $9,37 \mathrm{~cm}, 7,48 \mathrm{~cm}$ e $6,76 \mathrm{~cm}$, para os substratos Plantimax ${ }^{\circledR}$, vermiculita e fibra de coco, respectivamente, diferindo das sementes pequenas, com 4,61; 5,17 e 5,01 cm, nos respectivos substratos. O substrato Plantimax ${ }^{\circledR}$ proporcionou crescimento da parte aérea superior aos demais substratos quando se utilizaram sementes de tamanho médio. Segundo Klein et al. (2007a), testando três tamanhos de sementes em pitangueira, com diâmetros de $6 \mathrm{~mm}, 11$ $\mathrm{mm}$ e $14 \mathrm{~mm}$, observou-se que as sementes grandes e médias apresentaram maior comprimento de parte aérea do que as sementes pequenas. Em experimento em que os tratamentos eram a massa de 100 sementes, Klein et al. (2007b) obtiveram maiores valores de comprimento da parte aérea nas plântulas originárias de sementes de maior massa.

A utilização de sementes de tamanho médio proporcionou maior massa da matéria seca da parte aérea, raiz e também da massa da matéria seca total (Tabela 1). O substrato Plantimax ${ }^{\circledR}$ proporcionou $0,14 \mathrm{~g}, 0,07 \mathrm{~g}$ e $0,22 \mathrm{~g}$ para a massa seca da parte aérea, raiz e total, respectivamente, valores estes superiores aos que foram encontrados para o substrato fibra de coco.

Provavelmente, o melhor desempenho do substrato Plantimax ${ }^{\circledR}$, verificado no presente trabalho, esteja relacionado com suas propriedades químicas favoráveis ao desenvolvimento inicial das plantas. Os excelentes resultados obtidos com o substrato Plantmax ${ }^{\circledR}$, segundo Paulus et al. (2011),foram provavelmente em função das características físicas e 
químicas, principalmente por ser menos denso $(0,44$ $\left.\mathrm{g} \mathrm{cm}^{-3}\right)$, ter maior porosidade total $(78 \%)$ e valor mais elevado de CTC $(26,04)$, o que proporcionou maior capacidade de armazenamento e de fornecimento dos nutrientes às plantas.

Segundo Pio et al. (2005), a porosidade de aeração no substrato fibra de coco é maior do que no Plantimax ${ }^{\circledR}$ e na vermiculita. De acordo com Souza Júnior et al. (2008), a fibra de coco possui maior teor de nutrientes do que no Plantimax ${ }^{\circledR}$ para os elementos fósforo, potássio e sódio. Essas características físico-químicas do substrato fibra de coco podem ser favoráveis ao desenvolvimento das plantas; no entanto, segundo os mesmos autores, o teor de nitrogênio $(\mathrm{N})$ da fibra de coco é menor que no Plantimax ${ }^{\circledR}$,e o inverso para o carbono (C). Os teores de $\mathrm{C}$ e $\mathrm{N}$ da fibra de coco elevaram a relação $\mathrm{C} / \mathrm{N}\left(121 \mathrm{~g} \mathrm{~kg}^{-1}\right)$, sendo superior do que no Planti$\max ^{\circledR}\left(34 \mathrm{~g} \mathrm{~kg}^{-1}\right)$. Possivelmente, isto tenha relação com a velocidade de disponibilização de alguns nutrientes, como, por exemplo, o N, um dos grandes responsáveis pelo crescimento inicial da planta. Segundo Pons (1983), essa relação é importante no balanço da atividade microbiana, pois se for muito alta pode haver competição pelo $\mathrm{N}$ disponível entre os microrganismos e as plantas.

Experimento 2: A porcentagem de emergência mais elevada foi de $89,8 \%$ e ocorreu nos tratamentos cujas sementes foram provenientes da seleção 172 (Tabela 2), superioridade observada em todo o período de avaliação (Figura 1E). Valores similares de porcentagem de emergência foram encontrados por Masetto et al. (2007) e Silva et al. (2005). A menor porcentagem de emergência de sementes foi verificada na seleção 67 , possivelmente devido à menor qualidade destas (maturidade fisiológica ou de massa) não ter sido máxima. Segundo Castro et al. (2004), esta qualidade é medida pelo máximo peso seco da semente. De acordo com Avila et al. (2009), em pitangueira, a massa seca das sementes durante a maturação fisiológica aumentou até 63 dias após a antese, tendendo a estabilizar após esse período. No entanto, a máxima germinação verificada por estes autores ocorreu aos 42 dias após a antese. Tendência inversa verificou-se com a massa seca dos frutos de pitangueiras- vermelhas que, segundo Santos et al. (2002), é menor na coloração verde-vermelha $(19,44 \%)$, comparada aos frutos completamente maduros (18,81\%).

Para a seleção 67, houve tendência de aumento da quantidade de sementes brocadas pela praga Atractomerus pitangae (Marshall), aumentando a quantidade de sementes não emergidas e mortas (Tabela 2). Nesta seleção, observou-se ainda maior percentual de sementes dormentes (11\%), diferindo da 172 (2,7\%) (Figura 1A). O percentual de dormência foi superior em sementes totalmente maduras (10,2\%), diferindo das parcialmente maduras $(3,7 \%)$ (Figura 1B). De acordo com Fowler e Sturion (2000), a formação da semente depende da ocorrência de uma série de processos fisiológicos, que vão desde a fertilização do óvulo até sua maturação. Zaratin (2002) confirmou, entre os efeitos da não germinação, os embriões fisiologicamente imaturos. No presente trabalho, possivelmente, a plena maturação fisiológica não ocorreu no mesmo período, nas duas seleções. Santos et al. (2002) observaram alterações fisiológicas durante a maturação de pitangas vermelha e roxa.

A maior quantidade de folhas nas plantas provenientes de sementes parcialmente maduras ocorreu devido à emergência ter sido antecipada em ambas as seleções, diferentemente das plantas provenientes de sementes totalmente maduras (Figura 1E).

Houve interação do estágio de maturação e seleções para a variável comprimento da parte aérea (Figura 1D), no qual somente se verificou diferença nas plantas provenientes de sementes parcialmente maduras na seleção 172 , nas quais o comprimento chegou a $3,9 \mathrm{~cm}$. Possivelmente, por não ser uma semente de maturação fisiológica máxima, não ocorreu assim um perfeito equilíbrio hormonal, favorecendo com isso menor dominância apical da nova planta. Dantas et al. (2002) descrevem que as mudanças no equilíbrio hormonal em sementes podem resultar na influência exercida de um fitorregulador sobre níveis endógenos de outro. Zaratin (2002) descreveu em revisão de literatura que altos níveis de giberelinas são encontrados em sementes imaturas. Estes hormônios estimulam a enzima alfa-amilase e outras enzimas, promovendo a hidrólise do material de reserva, promovendo a conversão de amido em açúcar, que é usado para o crescimento da plântula. 


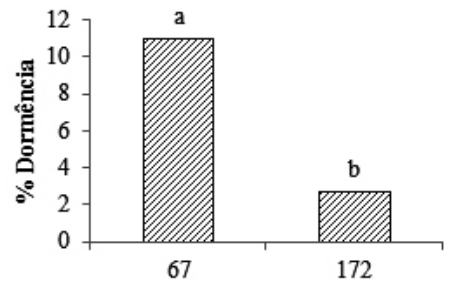

Seleção de pitangueira

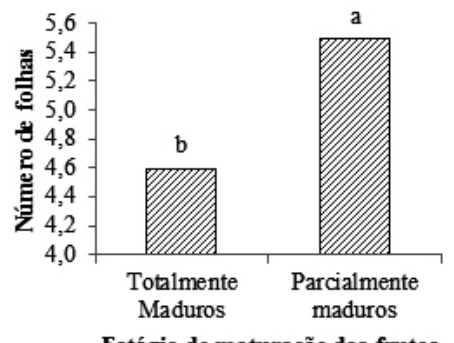

Estágio de maturação dos frutos

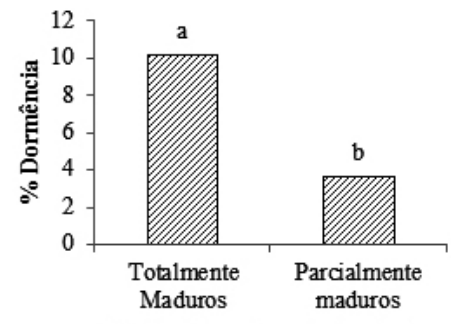

Estágio de maturação dos frutos

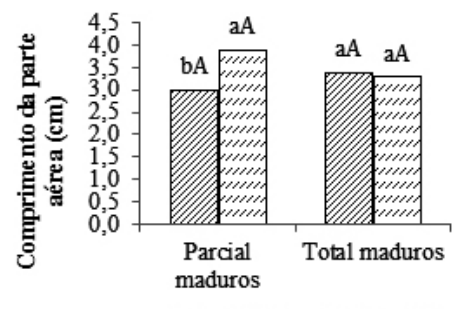

๒ Seleção 67 ๒Seleção 172

Estágio de maturação dos frutos

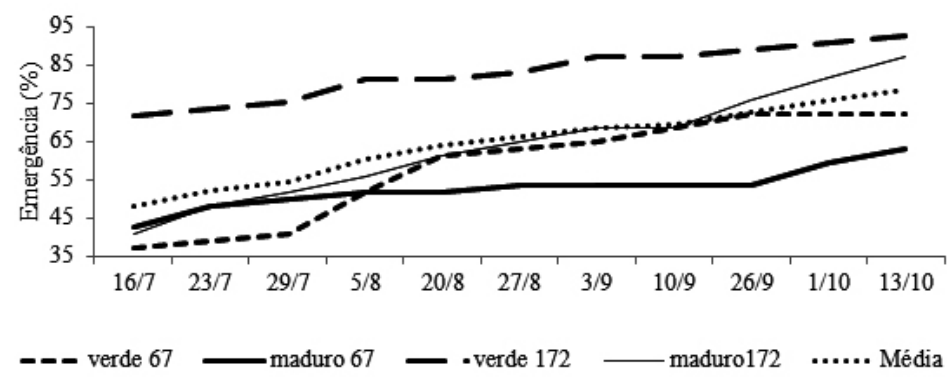

FIGURA 1 - Dormência (\%) de seleções de pitangueira (A) e de maturação de frutos (B), número de folhas em plantas (C), Comprimento da parte aérea (D) e emergência acumulada (E) e seu comportamento no período de avaliação, Embrapa Clima Temperado, Pelotas-RS, 2012.

Médias seguidas por letra distinta, maiúscula para maturação de fruto e minúscula para seleção, diferem estatisticamente entre si pelo teste Tukey, ao nível de $5 \%$ de probabilidade . 
TABELA 1 - Porcentagem de emergência (EM), número de folhas por planta (NF), comprimento da maior raiz (CR) e massa da matéria seca da parte aérea (MMSPA), da raiz (MMSR) e total (MMST) em diferentes tamanhos de sementes e substratos. Embrapa Clima Temperado, Pelotas-RS, 2012.

\begin{tabular}{|c|c|c|c|c|c|c|}
\hline Tamanho da Semente & EM (\%) & NF & CR $(\mathrm{cm})$ & MMSPA (g) & MMSR (g) & MMST (g) \\
\hline Média (10 mm) & $80,55 \mathrm{a}^{*}$ & $8,96 \mathrm{a}$ & $15,65 \mathrm{a}$ & $0,16 a^{*}$ & $0,08 \mathrm{a}$ & $0,25 \mathrm{a}$ \\
\hline Pequena $(6 \mathrm{~mm})$ & $27,77 \mathrm{~b}$ & $7,16 \mathrm{~b}$ & $12,79 \mathrm{~b}$ & $0,06 \mathrm{~b}$ & $0,03 \mathrm{~b}$ & $0,10 \mathrm{~b}$ \\
\hline \multicolumn{7}{|l|}{ Substrato } \\
\hline Plantimax $^{\circledR}$ & $58,33 \mathrm{a}$ & $9,44 \mathrm{a}$ & $15,40 \mathrm{a}$ & $0,14 \mathrm{a}$ & $0,07 \mathrm{a}$ & $0,22 \mathrm{a}$ \\
\hline Vermiculita & 57,29 a & $7,98 \mathrm{~b}$ & $14,64 \mathrm{a}$ & $0,11 \mathrm{ab}$ & $0,06 \mathrm{ab}$ & $0,17 \mathrm{ab}$ \\
\hline Fibra de Coco & $46,87 \mathrm{a}$ & $6,76 \mathrm{~b}$ & $12,61 \mathrm{a}$ & $0,09 \mathrm{~b}$ & $0,05 \mathrm{~b}$ & $0,14 \mathrm{~b}$ \\
\hline$\overline{C V}(\%)$ & 25,51 & 13,75 & 21,06 & 31,98 & 29,13 & 29,72 \\
\hline \multirow{2}{*}{ Substrato } & \multicolumn{6}{|c|}{ Comprimento da parte aérea $(\mathrm{cm})$} \\
\hline & Semente & Pequen: & $(6 \mathrm{~mm})$ & Sement & e Média (10 & $0 \mathrm{~mm})$ \\
\hline Plantimax ${ }^{\circledR}$ & \multicolumn{3}{|c|}{$4,61 \mathrm{aB}$} & \multicolumn{3}{|c|}{$9,37 \mathrm{aA}$} \\
\hline Vermiculita & \multicolumn{3}{|c|}{$5,17 \mathrm{aB}$} & \multicolumn{3}{|c|}{$7,48 \mathrm{bA}$} \\
\hline Fibra de Coco & \multicolumn{3}{|c|}{$5,01 \mathrm{aB}$} & \multicolumn{3}{|c|}{$6,76 \mathrm{bA}$} \\
\hline$\overline{C V}(\%)$ & & & 13,54 & & & \\
\hline
\end{tabular}

* Médias seguidas de mesma letra, minúscula na coluna e maiúscula na linha, não diferem entre si, pelo teste de Tukey, ao nível de 5\% de probabilidade.

TABELA 2 - Porcentagem de plântulas emergidas, sementes brocadas não emergidas, germinadas não emergidas (GNE) e mortas, nas seleções de pitangueira 67 e 172. Embrapa Clima Temperado, Pelotas-RS, 2012.

\begin{tabular}{ccccc}
\hline & & \multicolumn{3}{c}{ Sementes (\%) } \\
\cline { 3 - 5 } Seleção & Emergência (\%) & Brocadas** & GNE & Mortas \\
\hline 67 & $67,6 \mathrm{~b}^{*}$ & $8,2^{\text {ns }}$ & $10,1^{\text {ns }}$ & $2,7^{\text {ns }}$ \\
172 & $89,8 \mathrm{a}$ & 2,8 & 4,6 & 0,0 \\
\hline Maturação do fruto & & & & \\
\hline Parcial & $82,4^{\text {ns }}$ & $5,5^{\text {ns }}$ & $9,1^{\text {ns }}$ & $2,7^{\text {ns }}$ \\
Total & 75,0 & 5,4 & 5,5 & 0,0 \\
\hline CV $(\%)$ & 12,0 & 3,0 & 2,5 & 1,3 \\
\hline
\end{tabular}

*Letras minúsculas distintas na mesma coluna diferem estatisticamente entre si, pelo teste de Tukey, ao nível de 5\% de probabilidade. ** Ataque da praga Atractomerus pitangae (Marshall).

ns-não significativo

\section{CONCLUSÃO}

A utilização de sementes de tamanho médio e uso do substrato Plantimax ${ }^{\circledR}$ proporcionam melhor desenvolvimento inicial de mudas de pitangueira. $\mathrm{O}$ grau de maturação dos frutos afeta o processo de dormência das sementes e o desenvolvimento inicial das mudas de pitangueira.

\section{AGRADECIMENTOS}

Os autores agradecem o apoio financeiro recebido da Capes programa PNPD.

\section{REFERÊNCIAS}

AVILA, A. L. D.; ARGENTA, M. D. S.; MUNIZ, M. F. B.; POLETO, I.; BLUME, E. Maturação fisiológica e coleta de sementes de Eugenia uniflora L. (pitanga), Santa Maria, RS. Ciência Florestal, Santa Maria, v. 19, n. 1, p. 61-68, 2009. Disponível em: $<$ http://www.sumarios.org/sites/default/files/ pdfs/27616_3656.PDF $>$. Acesso em: 23 fev. 2012.

CARVALHO, N. M.; NAKAGAWA, J. Sementes: ciência, tecnologia e produção. 4.ed. Jaboticabal: Funep, 2000. 588 p. 
CASTRO, R. D. ; BRADFORD, K. J.; HILHORST, H. W. M. Desenvolvimento de sementes e conteúdo de água. In: FERREIRA, A. G.; BORGHETTI, F. Germinação: do básico ao aplicado. Porto Alegre: Artmed, 2004. cap. 3, p. 51- 67.

DANTAS, A. C. D. M.; MORAES, L. K. A. D.; PEDROTTI ENIO, L.; NODARI, R. O.; GUERRA, M. P. Superação in vitro da dormência de embriões do porta-enxerto de macieira M9 (Malus pumilla Mill.). Revista Brasileira de Fruticultura. Jaboticabal, v.24, n.1, p. 10-14. 2002.

DIAS, D. C. F. Maturação de sementes. Seed News. Pelotas, v.5, n.6, p.22-24, 2001.

DONADIO, L. C. Dicionário das frutas. Jaboticabal: FUNEP, 2007. 300p.

FOWLER, J. A. P.; STURION, J. A. Aspectos da formação do fruto e da semente na germinação da erva-mate. Colombro: Embrapa Florestas, 2000. p.1-5. (Comunicado Técnico, 45)

KAMPF, A. N. Produção comercial de plantas ornamentais. Guaíba: Agropecuária, 2000. 254 p.

KLEIN, J.; ZUCARELI V.; KESTRING, D.; CAMILLI, L.; RODRIGUES, J. D. Efeito do tamanho da semente na emergência e desenvolvimento inicial de mudas de pitangueira (Eugenia uniflora L.). Revista Brasileira de Biociências, Porto Alegre, v. 5, supl. 2, p. 861-863, 2007a.

KLEIN, J.; ZUCARELI V.; KESTRING, D.; RODRIGUES, J. D. Influência da massa das sementes na emergência e desenvolvimento inicial de mudas de pitangueira. Revista Brasileira de Biociências, Porto Alegre, v. 5, supl. 2, p. 837-839, 2007b. Disponível em: <http://www6.ufrgs.br/ seerbio/ojs/index.php/rbb/article/viewFile/699/589>. Acesso em: 23 fev. 2012.

LIRA JÚNIOR, J. S. BEZERRA, J. E. F.; LEBERMAN, I. E.; SILVA JUNIOR, J. F. D. Pitangueira. Recife: Liceu, 2007. 87p.

LORENZI, H. Árvores brasileiras: manual de identificação e cultivo de plantas arbóreas nativas do Brasil. 5.ed. Nova Odessa: Instituto Plantarum, 2008. v.1.368p.
MACHADO, A. A.; CONCEIÇÃO, A. R. Sistema de análise estatística para Windows. Winstat. Versão 2.0. Pelotas: UFPel, 2003.

MASETTO, T. E.; DAVIDE, A. C.; SILVA, E. A. A. D.; FARIA, J. M. Avaliação da qualidade de sementes de Eugenia pleurantha (Myrtaceae) pelo teste de raios x. Revista Brasileira de Sementes, Londrina, v. 29, n. 3, p. 170-174, 2007. Disponível em: <http://www.scielo.br/scielo.php?script=sci_ar ttext\&pid $=$ S0101-31222007000300020 $>$. Acesso em: 23 fev. 2012.

OLIVEIRA, I. V. de M.; COSTA, R. S.; ANDRADE, R. A.; MARTINS, A. B. G. Influencia do tamanho da semente na emergência das plântulas de Longan (Dimocarpos longan). Revista Brasileira de Fruticultura, Jaboticabal, v. 27, n. 1, p. 171-172, 2005. Disponível em: <http://www.scielo.br/pdf/rbf/ v27n1/24594.pdf $>$. Acesso em: 23 fev. 2012.

PAULUS, D; VALMORBIDA, R.; TOFFOLI, E.; PAULUS, E.; GARLET, T.M.B. Avaliação de substratos orgânicos na produção de mudas de hortelã (Mentha gracilis $\mathrm{R}$. Br. e Mentha x villosa Huds.). Revista brasileira de plantas medicinais, Botucatu, v.13, n.1, p. 90-97, 2011. Disponível em: $<$ http://www.scielo.br/scielo.php?pid=S151605722011000100014\&script $=$ sci_arttext $>$. Acesso em: 23 fev. 2012.

PIO, R.; ARAÚJO, J. P. C. de; BASTOS, D. C.; AlVES, A. S. R.; ENTELMANN, F. A.; SARPARE FILHO, J. A.; MOURÃO FILHO, F. de A. A. Substratos no enraizamento de estacas herbáceas de figueira oriundas da desbrota. Ciência e Agrotecnologia, Lavras, v. 29, n. 3, p. 604-609, 2005. Disponível em: <http://www.scielo.br/pdf/ cagro/v29n3/a14.pdf>. Acesso em: 23 fev. 2012.

POPINIGIS, F. Fisiologia da semente. Brasília: AGIPLAN, 1985. 289 p.

PONS, A. L. Fontes e uso da materia orgânica. IPAGRO Informa, Porto Alegre, v.1, n. 26, p. 111147, 1983 .

RASEIRA, M. C. B.; ANTUNES, L. E. C.; TREVISAN, R.; GONÇALVES, E. D. Espécies frutíferas nativas do Sul do Brasil. Pelotas: Embrapa-CPACT, 2004. (Documentos, 129) 
SANTOS, A. F.; SILVA, S. D. M.; MENDONÇA, R. M. N.; SILVA, M. S. D. Alterações fisiológicas durante a maturação de pitanga (Eugenia uniflora L.), Proceedings of The Interamerican Society For Tropical Horticulture, v. 46, p. 52-54, 2002. Disponível em: $<$ http://www.ceinfo.cnpat.embrapa. br/arquivos/artigo_1582.pdf $>$. Acesso em: $23 \mathrm{fev}$. 2012.

SARTOR, F. R.; MÜLLER, N. T. G.; MORAES, A. M. D. Efeito do ácido indolbutírico e de substratos na propagação de estacas e sementes de jabuticabeira. Tecnologia \& Ciência. Agropecuária, Paraíba, v.4, n.3, p. 11-15, 2010. Disponível em: <http://emepa. org.br/revista/volumes/tca v4 n 3 sst/tca03 acido. pdf $>$. Acesso em: 23 fev. 2012.

SILVA, C. V. E; BILIA, D. A. C.; BARBEDO, C. J. Fracionamento e germinação de sementes de Eugenia. Revista Brasileira de Sementes, Viçosa, MG, v. 27, n. 1, p.86-92, 2005. Disponível em: $<$ http://www.scielo.br/scielo.php?pid=S0101$31222005000100011 \&$ script $=$ sci arttext $>$. Acesso em: 23 fev. 2012.
SOUZA JÚNIOR, J. O. D.; CARMELLO, Q. A. D. C.; FARIA, J. C. Características químicas do lixiviado na fase de enraizamento de estacas de cacau em substratos adubados com fósforo. Revista Brasileira Ciência do Solo, Viçosa, MG, v. 32 , n. 4, p. 1573-1581, 2008. Disponível em: $<$ http://www.scielo.br/scielo.php?pid=S0100$06832008000400021 \&$ script $=$ sci_arttext $>$. Acesso em: 23 fev. 2012.

ZARATIN, C. Armazenamento das sementes associado a embebição, hormônios e $\mathrm{KNO}_{3}$ na germinação e desenvolvimento inicial de mudas de Passiflora alata Dryander. Ilha Solteira 2002. 69 f. Dissertação (Mestrado em Agronomia/Produção Vegetal) - Faculdade de Engenharia de Ilha Solteira, Universidade Estadual Paulista, Ilha Solteira, 2002. 